\title{
Morpho-constitutional analysis of urinary stones from patients with urolithiasis in the Democratic Republic of Congo
}

Pablo Kuntima Diasiama Diangienda ${ }^{1 *} \mathbb{C}$, Dieudonné Molamba Moningo ${ }^{1}$, Jean-Robert Rissasy Makulo², Ernest Kiswaya Sumaili², Eric Musalu Mafuta ${ }^{3}$, Alain Ngoma Mayindu ${ }^{4}$, Augustin M. L. Punga-Maole?, Jean-Philippe Haymann ${ }^{5}$ and Michel Daudon ${ }^{5}$

\begin{abstract}
Background: Urolithiasis is increasingly diagnosed worldwide. Stone analysis is an important part in the assessment of patients with urolithiasis. However, in sub-Saharan Africa, data on the composition of urinary stones are limited. This study aimed to describe the composition and sites of urinary stones and to investigate relationship between sociodemographic characteristics, clinical profile of patients, and the composition of urinary stones.

Methods: A retrospective analysis of 132 patients with urolithiasis who visited one of the seven hospitals in the Democratic Republic of Congo during eight years of study period (January 2010 to January 2018) was conducted. Stones were analyzed by infrared spectrophotometry.

Results: Most of stones analyzed $(n=82,62.1 \%)$ originated from the upper urinary tract with a difference across gender ( $58.5 \%$ males vs. $41.5 \%$ females, $p=0.001$ ). Only three stones (two from whewellite and one from anhydrous uric acid) were considered pure (2.3\%), excluding the protein frame (less than 5\%). Whewellite, proteins, and carbapatite were identified in $97.7 \%, 96.2 \%$, and $80.3 \%$ of the stones analyzed, respectively; and in $91.7 \%, 89.4 \%$, and $67.7 \%$ of the nuclei of the stones analyzed, respectively. Taking into account the proportion of each constituent in the stones analyzed, whewellite (68.9\%), anhydrous uric acid (10.6\%), and carbapatite (8.3\%) were the main constituents in respectively $68,9 \%, 10.6 \%$, and $8.3 \%$ of the stones analyzed.
\end{abstract}

Conclusion: Whewellite, anhydrous uric acid, and carbapatite represented the most frequent main components of stones identified, suggesting that dietary hyperoxaluria could be an important factor in lithogenesis in the Democratic Republic of Congo.

Keywords: Urinary stones, Morphology, Chemical composition, Etiological factors

\section{Background}

Urolithiasis is a major common health problem characterized by the formation or occurrence of stones in the urinary tract. Its prevalence and incidence are constantly increasing worldwide, especially in Western countries

\footnotetext{
*Correspondence: pablodiang@gmail.com

1 Department of Urology, Faculty of Medicine, University Hospital

of Kinshasa, Kinshasa, Democratic Republic of Congo

Full list of author information is available at the end of the article
}

[1]. Nearly one of ten Europeans has at least one urinary stone in his lifetime [1-4]; in North America, the prevalence of this condition is estimated around $7-13 \%$ and in Asia from 1 to 5\% [5]. In Africa, despite the lack of large epidemiological studies, hospital data reported an increasing number of urolithiasis cases $[6,7]$.

It is known that urolithiasis has a high potential for recurrence, hence the need to identify the chemical and crystalline composition of urinary stones to initiate adequate preventive measures [1]. This identification is 
currently done by a morpho-constitutional analysis using physical methods such as microscopic analysis associated with infrared spectrophotometry [8], which are expensive techniques and not yet available in the Democratic Republic of Congo (DRC).

In a monocentric study conducted in Kinshasa city [9], in addition to the increase in the frequency of urolithiasis, whewellite (calcium oxalate monohydrate) was identified by authors as the most frequent chemical component of stones. However, large and inclusive data are needed. Therefore, we conducted a multi-centric-study aiming at describing the sites and composition of urinary stones and investigating relations between socio-demographic characteristics, clinical profile of patients, and the composition of urinary stones.

\section{Methods}

\subsection{Design, setting, period, and study population}

This was a retrospective analysis conducted among 132 patients with urolithiasis who visited one of the seven hospitals in the DRC from January 2010 through January 2018. All stones samples collected from various hospitals were sent at the Functional Explorations Department of a Parisian hospital for morpho-constitutional analysis.
Hospitals included five from Kinshasa and two from two provinces (Kongo Central and South Kivu).

The sample size was not predetermined in the initial phase of the study, and the study included 132 patients easily accessible in hospitals who agreed to collaborate. The sample approach was carried out by reasoned or strategic choice. The number of stones per patient was only used to determine the average, in the description of the chemical constituents of the stones, only one stone per patient was taken into account because the chemical composition (of these multiple stones of the same site in a patient) was stackable. Only whole stones were taken into account to determine the average number of stones per patient.

\subsection{Morpho-constitutional analysis of stones}

The morphological study of the stones was carried out by microscopic examination using a stereo microscope. We used the morpho-constitutional classification of Daudon et al. (Table 1) to classify stones [8].

The different morphological types of the surface and the nucleus of stones were distinguished in simple morphology and in morphological association (the existence of at least two different morphological subtypes within the stones). Different layers of stones were analyzed by

Table 1 Morpho-constitutional classification of the stones according to Daudon et al.

\begin{tabular}{|c|c|c|c|}
\hline Morphological type & Subtype & Component & Clinical interpretation \\
\hline \multirow[t]{5}{*}{ । } & la & Whewellite & Dietary hyperoxaluria, insufficient diuresis \\
\hline & $\mathrm{Ib}$ & Whewellite & Stase, insufficient diuresis \\
\hline & IC & Whewellite & Primary hyperoxaluria \\
\hline & Id & Whewellite & Malformative uropathy, stasis and anatomical confinement \\
\hline & le & Whewellite & Hyperoxalurie absorptive \\
\hline \multirow[t]{3}{*}{$\|$} & $\| a$ & Weddellite & Hypercalciurie \\
\hline & $\mathrm{Ilb}$ & Weddellite \pm whewellite & Hypercalciuria \pm hyperoxaluria \pm hypocitraturia \\
\hline & Ilc & Weddellite & Hypercalciuria, stasis and anatomical confinement \\
\hline \multirow[t]{4}{*}{ III } & IIla & Uric acid & acid urinary $\mathrm{pH}$ and stasis \\
\hline & $\mathrm{lllb}$ & Uric acid & Metabolic syndrome, diabetes \\
\hline & IIIC & Urates & Hyperuricosuria and alkaline urine, urinary tract infection \\
\hline & Illd & Ammonium urate & Hyperuricosuria and diarrhea \\
\hline \multirow[t]{5}{*}{ IV } & IVa1 & Carbapatitis & Hypercalciuria, urinary tract infection \\
\hline & IVa2 & Carbapatitis & Distal tubular acidosis \\
\hline & $\mathrm{IVb}$ & Carbapatitis & Infection, hypercalciuria \\
\hline & IVC & Struvite & Urease germ infection \\
\hline & $\mathrm{IVd}$ & Brushitis & $\begin{array}{l}\text { Hypercalciuria, primary hyperparathyroidism, hyperphos- } \\
\text { phaturia, phosphated diabetes }\end{array}$ \\
\hline \multirow[t]{2}{*}{ V } & Va & Cystine & Cystinuria \\
\hline & $\mathrm{Vb}$ & Cystine & Cystinuria + alkalization treatment \\
\hline \multirow[t]{3}{*}{$\mathrm{VI}$} & Vla & Proteins & Chronic pyelonephritis \\
\hline & $\mathrm{Vlb}$ & Proteins & Drug lithiasis and tubular protein secretion or proteinuria \\
\hline & Vlc & Proteins & Dialysis and excessive calcium + vitamin D supplementation \\
\hline
\end{tabular}


Fourier transform infrared spectrophotometry (Vector 22 FT-IR spectrophotometer, Bruker Optics, Champssur-Marne, France) in absorbance mode by accumulation of 32 spectra between 4000 and $400 \mathrm{~cm}^{-1}$, with a resolution of $4 \mathrm{~cm}^{-1}$ according to the technique of pastillage with potassium bromide.

Stone cut with less effort with a scalpel was considered medium hardness, while the section of the hard stone required the use of two hands in support. As for the very hard stone, its section required the use of a wood chisel and a hammer. Only the large diameter of the stones was taken into account in the morphological analysis. For every stone, the components of stones were determined, the main components (chemical or crystalline body representing the large proportion in a stone) and nucleus components of stones. Finally, various main constituents were classified based on their chemical structure: calcium oxalate $(\mathrm{CaOx})$, phosphates, purines, and cystine.

Demographic variables collected for the study included: age, gender, place of residence, body mass index (BMI), province of origin, profession, sites of the stones, and their mode of elimination. The place of residence was divided in two categories: Kinshasa and other provinces. Provinces of origin were classified into 4 major geographic groups: the West, the North, the Center-South, and the East.

\subsection{Statistical analysis}

Continuous variables were expressed as means and medians. Categorical variables were summarized into proportions. Differences in categorical variables between groups were assessed using Chi-square test or the chi-square likelihood-ratio as appropriate. Differences in means were assessed by the student's $t$ test. $P$ values less or equal to 0.05 were interpreted as statistically significant. Statistical analysis was performed using SPSS Statistics software version 22 (IBM, Armonk, USA).

\section{Results}

\subsection{Frequency of stones and socio-demographic and clinical parameters.}

Whole or fragmented stones from 132 patients were analyzed at the Functional Explorations Department. The mean $( \pm S D)$ number of whole stones removed per patient was 1.5 (2.1) with a median of one. Most participants were adults $(95 \%, n=126)$ and males $(72 \%, n=95)$. The mean $( \pm S D)$ age of the patients was 48.1 (17.1) years.

Eighty-two stones $(62.1 \%)$ were located in the upper urinary tract (Table 2). Of these, 42 (51.2\%) were located on the left side, 39 (47.6\%) on the right side, and one $(0.8 \%)$ bilaterally. Sites of kidney stones were associated with their lateralization $(p=0.032)$.

The frequency of stones from the lower urinary tract was highest among those 60-years-old or older $(p<0.001)$. Compared to males, females had 11 times more calculi from the upper tract than from the low tract $(p<0.001)$. Of the stones removed spontaneously, $8(80 \%)$ were initially located in the upper tract (Table 2).

\subsection{Morphological analysis}

On average, most of stones were $20 \pm 17.2$-mm-diameter and median of $16.5 \mathrm{~mm}$. Fifty-three percent of stones were hard, $39.4 \%$ very hard, and the remaining were of medium hardness. Two stones $(1.5 \%)$ were enucleated on

Table 2 General characteristics of the study population by sites of stones

\begin{tabular}{|c|c|c|c|c|}
\hline Variables & Over all $n=132$ (\%) & Upper tract $n=82(\%)$ & Lower tract $n=50(\%)$ & $p$ \\
\hline Age & $48.1 \pm 17.1$ & $45.1 \pm 14.3$ & $53.1 \pm 20.1$ & $<0.001$ \\
\hline$\leq 19$ years & $6(4.5)$ & $1(1.2)$ & $5(10.0)$ & \\
\hline 20-39 years & $38(28.8)$ & $32(39.0)$ & $6(12.0)$ & \\
\hline $40-59$ years & $49(37.1)$ & $36(43.9)$ & 13(26.0) & \\
\hline$\geq 60$ years & $39(29.5)$ & 13(15.9) & $26(52.0)$ & \\
\hline Sex & & & & $<0.001$ \\
\hline Female & $37(28.0)$ & $34(41.5)$ & $3(6.0)$ & \\
\hline Male & $95(72.0)$ & $48(58.5)$ & $47(94.0)$ & \\
\hline BMl & & & & 0.852 \\
\hline Normal & 28(43.8) & $17(41.5)$ & $11(47.8)$ & \\
\hline Overweight & $28(43.8)$ & 19(46.3) & $9(39.1)$ & \\
\hline Obesity & $8(12.5)$ & $5(12.2)$ & $3(13.0)$ & \\
\hline Treatment modalities & & & & 0.150 \\
\hline Open surgery & 117(88.6) & $69(84.1)$ & 48(96.0) & \\
\hline Endoscopy & $5(3.8)$ & $5(6.1)$ & $0(0.0)$ & \\
\hline Spontaneous & 10(7.6) & $8(9.8)$ & $2(4.0)$ & \\
\hline
\end{tabular}


a probe, and a Randall plate (Fig. 1a and b) was found on three stones (2.3\%).

On their surface, 59 stones had a unique morphological type, and 73 stones exhibited morphological associations. In the nucleus, a single morphological type was observed for 83 stones.

$\mathrm{CaOx}$ was the most common component. Type I, corresponding to whewellite $(\mathrm{CaOx}$ monohydrate), was the simple morphological type most frequently found in males and females, both on the surface and in the nucleus. In females, it accounted for $53.3 \%$ of all simple morphological types of the surface and $40.0 \%$ of simple morphologies of the nucleus. The subtype Ia was predominant in both sexes on the surface of stones $(41.7 \%$ in females and $21.3 \%$ in males). The subtype Ib was predominant in the stone nucleus $(25.0 \%$ in females and $34.9 \%$ in males) (Table 3). The subtype app.Ic, which suggests active hyperoxaluria, was identified on the surface of two stones and in the nuclei of four stones.

Type IV was the second most frequently identified morphological type in the nuclei in both sexes $(30.0 \%$ in females and $20.6 \%$ in males). The subtype IVa was predominant in the nuclei while the subtype IVb was predominant on the surface.

Finally, only one type Va stone, corresponding to cystine, was observed in males (Table 3).

Among the morphological associations (Table 4), the oxalocalcic mixtures I+ II (48\% in females and 50\% in males) and phosphatic or oxalo-phosphatic (40\% in females and $37.5 \%$ in males) were by far the most frequent on the surfaces of stones. Morphological associations comprising type IV were identified in $41.2 \%$ and $65.6 \%$ in the stone nuclei females and males, respectively.

\subsection{Infrared analysis \\ 3.3.1 Different constituents identified in stones}

Infrared analysis of the different layers of the stones identified 618 constituents. The average $( \pm S D)$ number of components per stone was 4.7 (1.2). Only three stones (two from whewellite and one from anhydrous uric acid) could be deemed pure (2.3\%), excluding the protein frame (less than 5\%). Without taking into account its proportion in the stones, the whewellite was the most frequent constituent in stones analyzed. With an average $( \pm \mathrm{SD})$ content in the stones of 58.0\% (32.7) (a median of 66.5), the whewellite was identified in 129 (97.7\%) stones analyzed. Whewellite was also present in $94.5 \%$ of nuclei stones in females and $90.5 \%$ in males. Proteins were identified in $127(96.2 \%)$ stones. The average $( \pm S D)$ proportion of proteins in stones was very low [4.5\% (3.2)]. Carbapatite was the third most common component, identified in 106 stones (80.3\%). Weddellite, ammonium acid urate, and struvite were identified in $43.2 \%, 23.5 \%$, and $21.2 \%$ of the stones analyzed, respectively (Table 5).

\subsubsection{Main components of stones}

Whewellite was the most frequent main component of stones analyzed. Overall, it was identified as the main component in 91 (68.9\%) of stones. In females, whewellite was the main component of 27 stones $(73.0 \%)$, and in males, it was the main component of 64 stones $(67.4 \%)$.

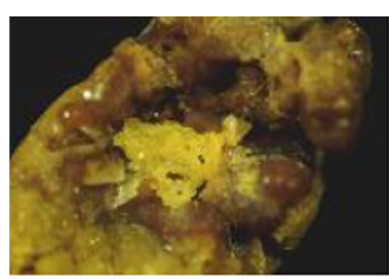

a

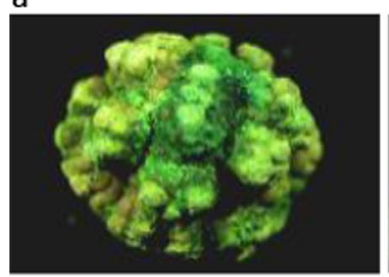

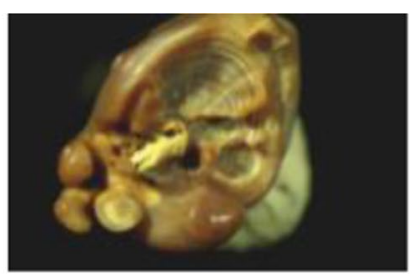

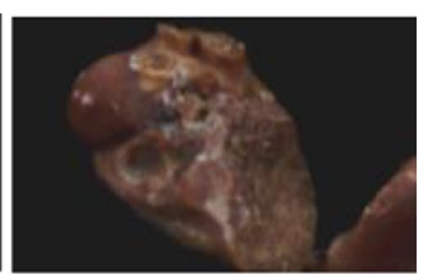

b
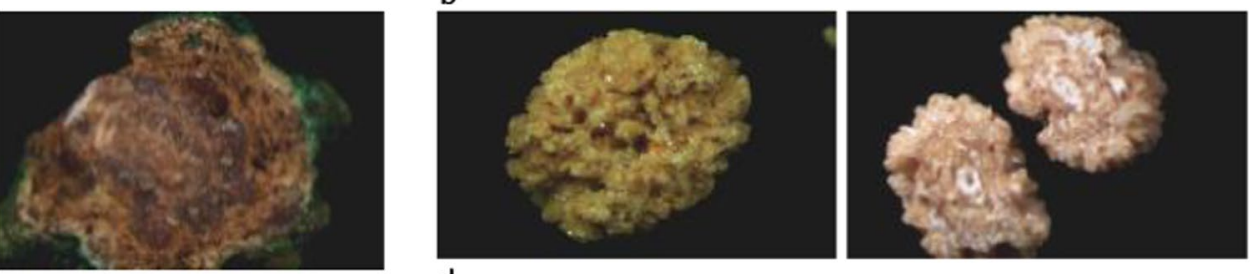

d

Fig. 1 Illustration of some stones analyzed a stone surgically extracted from the right ureter of $12 \mathrm{~mm}$ in diameter, irregular shape with Randall's plate, morphology $\mathrm{llb}+\mathrm{la} \mathbf{b}$ stone of the right ureter of $5.5 \mathrm{~mm}$ in diameter, irregular shape, morphology la with Randall's plate c stone extracted from the bladder of $10 \mathrm{~mm}$ in diameter of irregular shape and hilly surface, bluish to dark brown (la $+\mathrm{VIb})$. Heterogeneous section, periphery $\mathrm{lb}+\mathrm{VIb}$ and depth la. Non-individualized nucleus (la). $\mathbf{d}$ calculus spontaneously eliminated from the left ureter of a patient $6 \mathrm{~mm}$ in diameter, oval with a crystalline surface, spiculated light brown-yellow (lla) 
Table 3 Simple morphological types of urinary stones by sex

\begin{tabular}{|c|c|c|c|c|}
\hline \multirow[t]{2}{*}{ Morphology } & \multicolumn{2}{|l|}{ Superficial } & \multicolumn{2}{|l|}{ Nucleus } \\
\hline & Female $n=12(\%)$ & Male $n=47(\%)$ & Female $n=20(\%)$ & Male $n=63(\%)$ \\
\hline । & $7(53.3)$ & $20(42.5)$ & $8(40.0)$ & $26(41.3)$ \\
\hline app.lc & $1(8.3)$ & $1(2.1)$ & $2(10.0)$ & $2(3.2)$ \\
\hline l act & $0(0.0)$ & $2(4.2)$ & $0(0.0)$ & $2(3.2 \%)$ \\
\hline la & $5(41.7)$ & 10(21.3) & $1(5.0)$ & $0(0.0 \%)$ \\
\hline lb & $0(0.0)$ & $0(0.0)$ & $5(25.0)$ & $22(34.9)$ \\
\hline Id & $1(8.3)$ & $4(8.5)$ & $0(0.0)$ & $0(0.0)$ \\
\hline $\mathrm{la} / \mathrm{d}+\mathrm{ld} / \mathrm{a}$ & $0(0.0)$ & $3(6.4)$ & $0(0.0)$ & $O(0.0)$ \\
\hline$\|$ & $0(0.0)$ & $8(17.0)$ & $0(0.0)$ & $2(3.2)$ \\
\hline$\| \mathrm{a}$ & $0(0.0)$ & $2(4.2)$ & $0(0.0)$ & $0(0.0)$ \\
\hline$\| \mathrm{b}$ & $0(0.0)$ & $6(12.8)$ & $0(0.0)$ & $2(3.2)$ \\
\hline III & $0(0.0)$ & $9(19.1)$ & $3(15.0)$ & $14(22.2)$ \\
\hline IIIb & $0(0.0)$ & $4(8.5)$ & $1(5.0)$ & $8(12.7)$ \\
\hline IIIC & $0(0.0)$ & $5(10.6)$ & $0(0.0)$ & $3(4.8)$ \\
\hline IIld & $0(0.0)$ & $0(0.0)$ & $2(10.0)$ & $3(4.8)$ \\
\hline IV & $5(41.7)$ & $8(17.0)$ & $6(30.0)$ & 13(20.6) \\
\hline IVa & $1(8.3)$ & $4(8.5)$ & $5(25.0)$ & 12(19.1) \\
\hline $\mathrm{IVb}$ & $3(25.0)$ & $4(8.5)$ & $0(0.0)$ & $0(0.0)$ \\
\hline IVc & $1(8.3)$ & $0(0.0)$ & $1(5.0)$ & $1(1.6)$ \\
\hline V & $0(0.0)$ & $1(2.1)$ & $0(0.0)$ & $0(0.0)$ \\
\hline Va & $0(0.0)$ & 1(2.1) & $0(0.0)$ & $O(0.0)$ \\
\hline VI & $0(0.0)$ & $O(0.0)$ & $1(5.0)$ & $5(7.9)$ \\
\hline Vla & $0(0.0)$ & $0(0.0)$ & $0(0.0)$ & $1(1.6)$ \\
\hline VIb & $0(0.0)$ & $0(0.0)$ & $1(5.0)$ & $4(6.3)$ \\
\hline Others & $0(0.0)$ & $1(2.1)$ & $2(10.0)$ & $3(4.8)$ \\
\hline $\mathrm{INH}$ & $O(0.0)$ & $1(2.1)$ & $0(0.0)$ & $O(0.0)$ \\
\hline SD & $0(0.0)$ & $0(0.0)$ & $0(0.0)$ & $2(3.2)$ \\
\hline No Nx & $0(0.0)$ & $O(0.0)$ & $2(10.0)$ & 1(1.6) \\
\hline
\end{tabular}

In addition to whewellite, the other main components of stones analyzed included anhydrous uric acid (10.6\%), carbapatite $(8.3 \%)$, struvite $(5.3 \%)$, weddellite $(3.8 \%)$, ammonium urate $(2.3 \%)$, and cystine $(0.8 \%)$.

In females, the frequency of whewellite increased with age and was the main component of stones among 60 -years-old or older. In males, however, although it remained the largest main component across all age groups, its magnitude decreased with age. Carbapatite (16.2\%) and weddellite (5.4\%) were the other two main important components in females. In males, anhydrous uric acid (13.7\%) and struvite (6.3\%) were the other two main important components (Table 6).

\subsubsection{The main components regrouped,} the socio-demographic characteristics, clinical profile

Calcium oxalate (mono and dihydrate) was the most frequent $(72.7 \%)$, followed by phosphates $(13.6 \%)$ and purines $(12.9 \%)$.
The frequency of $\mathrm{CaOx}$ stones increased with age and peaked between 40 and 59 years before declining with the aging of the population. Purines showed a maximum after age $60(p=0.035)$. Purines were most frequent in patients living in Kinshasa $(p=0.001)$, they were associated with prostatic adenoma $(p=0.005)$ and preferentially located at the lower urinary tract $(p=0.001)$. Patients from the western part of the DRC had more $\mathrm{CaOx}$ stones, while those from the south-central and eastern part had more purine and phosphate stones, respectively $(p=0.008)$ (Table 7$)$.

\section{Discussion}

Our study aimed to determine the morpho-constitutional composition of urinary stones in a multicentric approach. Stones were mainly located in the upper urinary tract, they were heterogeneous and large in diameter. Whewellite (the predominant subtype Ia) was the preponderant main component, followed by anhydrous uric acid and carbapatite. Like whewellite, proteins (the predominant 
Table 4 Morphological description of urinary stones by gender

\begin{tabular}{|c|c|c|c|c|}
\hline \multirow[t]{2}{*}{ Morphology } & \multicolumn{2}{|l|}{ Superficial } & \multicolumn{2}{|l|}{ Nuleus } \\
\hline & Female $n=25(\%)$ & Male $n=48(\%)$ & Female $n=17(\%)$ & Male $n=32(\%)$ \\
\hline Mixed oxalo-calcium & $12(48.0)$ & $24(50.0)$ & $7(41.2)$ & $8(25.0)$ \\
\hline app.lc + IIb & $0(0.0)$ & $1(2.1)$ & $0(0.0)$ & $0(0.0)$ \\
\hline$|a c t+1| b$ & $3(12.0)$ & $2(4.2)$ & $0(0.0)$ & $0(0.0)$ \\
\hline $\mid a / b+11 b$ & $9(36.0)$ & $21(43.7)$ & $7(41.2)$ & $8(25.0)$ \\
\hline Mixed urique & $2(8.0)$ & $5(10.4)$ & $0(0.0)$ & $0(0.0)$ \\
\hline$|a / b+||| b / c$ & $2(8.0)$ & $5(10.4)$ & $0(0.0)$ & $0(0.0)$ \\
\hline Mixed type IV & $10(40.0)$ & $18(37.5)$ & $7(41.2)$ & $21(65.6)$ \\
\hline $\mathrm{la} / \mathrm{b} / \mathrm{INH}+\mathrm{IVa}$ & $3(12.0)$ & $6(12.5)$ & $4(23.5)$ & $4(12.5)$ \\
\hline$\| \mathrm{la} / \mathrm{b}+\mathrm{IVa}$ & $2(8.0)$ & $3(6.2)$ & $3(17.6)$ & $14(43.7)$ \\
\hline $\mathrm{IVa} / \mathrm{c}+\mathrm{IVc} / \mathrm{a}$ & $2(8.0)$ & $3(6.2)$ & $0(0.0)$ & $2(6.2)$ \\
\hline$|a / b+1| b+I V a$ & $3(12.0)$ & $4(8.3)$ & $0(0.0)$ & $1(3.1)$ \\
\hline Mixed type V & $0(0.0)$ & $0(0.0)$ & $0(0.0)$ & $1(3.1)$ \\
\hline $\mathrm{Va}+\mathrm{IVa}$ & $0(0.0)$ & $0(0.0)$ & $0(0.0)$ & $1(3.1)$ \\
\hline Mixed type VI & $1(4.0)$ & $1(2.1)$ & $3(17.6)$ & $2(6.2)$ \\
\hline $\mathrm{Vlb}+\mathrm{lb} / \mathrm{d}$ & $0(0.0)$ & $0(0.0)$ & $1(5.9)$ & $2(6.2)$ \\
\hline$V l b+I V a$ & $0(0.0)$ & $0(0.0)$ & $2(11.8)$ & $0(0.0)$ \\
\hline$V l b+l a / l b+l d / l l b$ & $1(4.0)$ & $1(2.1)$ & $0(0.0)$ & $0(0.0)$ \\
\hline
\end{tabular}

Table 5 Overall identification of the constituents of urinary stones and their nuclei according to gender

\begin{tabular}{|c|c|c|c|c|}
\hline \multirow[t]{2}{*}{ Constituents } & \multicolumn{2}{|l|}{ Overall composition } & \multicolumn{2}{|c|}{ Nucleus composition } \\
\hline & Female $n=37(\%)$ & Male $n=95(\%)$ & Female $n=37(\%)$ & Male $n=95(\%)$ \\
\hline \multicolumn{5}{|l|}{ Oxalate calcium } \\
\hline Whewellite & $37(100.0)$ & $92(96.8)$ & $35(94.5)$ & $86(90.5)$ \\
\hline Weddellite & $17(45.9)$ & $42(44.2)$ & $7(18.9)$ & 18(18.9) \\
\hline \multicolumn{5}{|l|}{ Phosphate } \\
\hline Carbapatite & $32(86.5)$ & 74(77.9) & $27(72.9)$ & $65(68.4)$ \\
\hline PACC & $6(16.2)$ & 19(20.0) & $4(10.8)$ & 12(12.6) \\
\hline OCP & $0(0.0)$ & $1(1.1)$ & $0(0.0)$ & $1(1.0)$ \\
\hline Struvite & $10(27.0)$ & 18(17.6) & $5(13.5)$ & $7(7.4)$ \\
\hline Newbéryite & $0(0.0)$ & $1(1.0)$ & $0(0.0)$ & $0(0.0)$ \\
\hline Whitlockite & $5(13.5)$ & 11(11.6) & $3(8.1)$ & $8(8.4)$ \\
\hline \multicolumn{5}{|l|}{ Purines } \\
\hline Anhydrous uric acid & $1(2.7)$ & 16(16.8) & $1(2.7)$ & 12(12.6) \\
\hline Ac. uric acid dihydrate & $1(2.7)$ & $0(0.0)$ & $0(0.0)$ & $O(0.0)$ \\
\hline Ammonium urate & $7(18.9)$ & $24(25.3)$ & $5(13.5)$ & 11(11.6) \\
\hline Unidentified urate & $1(2.7)$ & $0(0.0)$ & $0(0.0)$ & $0(0.0)$ \\
\hline Cystine & $0(0.0)$ & $1(1.0)$ & $0(0.0)$ & $1(1.0)$ \\
\hline \multicolumn{5}{|l|}{ Others } \\
\hline Proteins & $36(97.3)$ & $91(95.8)$ & 34(91.9) & $84(88.4)$ \\
\hline Mucopolysaccharides & $15(40.5)$ & $40(42.1)$ & 13(35.1) & $36(37.9)$ \\
\hline Triglycérides & $7(18.9)$ & 13(13.7) & $6(16.2)$ & 12(12.6) \\
\hline Urinary catheter & $0(0.0)$ & $2(2.1)$ & $0(0.0)$ & $2(2.1)$ \\
\hline
\end{tabular}


Table 6 Distribution of main types of stones according to age groups and gender

\begin{tabular}{|c|c|c|c|c|c|c|}
\hline \multirow[t]{2}{*}{ Sex } & \multirow[t]{2}{*}{ Types of stones } & \multicolumn{4}{|c|}{ Age (years) } & \multirow[t]{2}{*}{ Overall } \\
\hline & & $<19$ & $20-39$ & $40-59$ & $\geq 60$ & \\
\hline \multirow[t]{9}{*}{ Female } & Oxalate calcium & & & & & \\
\hline & Whewellite & $1(50.0)$ & $7(63.6)$ & 15(75.0) & $4(100.0)$ & $27(73.0)$ \\
\hline & Weddellite & $0(0.0)$ & $0(0.0)$ & $2(10.0)$ & $0(0.0)$ & $2(5.4)$ \\
\hline & Phosphates & & & & & \\
\hline & Carbapatite & $0(0.0)$ & $4(36.4)$ & $2(10.0)$ & $0(0.0)$ & $6(16.2)$ \\
\hline & Struvite & $1(50.0)$ & $0(0.0)$ & $0(0.0)$ & $0(0.0)$ & $1(2.7)$ \\
\hline & Purines & & & & & \\
\hline & Anhydrous uric acid & $0(0.0)$ & $0(0.0)$ & $1(5.0)$ & $0(0.0)$ & $1(2.7)$ \\
\hline & All & $2(100.0)$ & $11(100.0)$ & $20(100.0)$ & $4(100.0)$ & $37(100.0)$ \\
\hline \multirow[t]{11}{*}{ Male } & Oxalate calcium & & & & & \\
\hline & Whewellite & $3(75.0)$ & 21(77.8) & $20(69.0)$ & $20(57.1)$ & $64(67.4)$ \\
\hline & Weddellite & $0(0.0)$ & $2(7.4)$ & $1(3.4)$ & $0(0.0)$ & $3(3.2)$ \\
\hline & Phosphates & & & & & \\
\hline & Carbapatite & $0(0.0)$ & $2(7.4)$ & $0(0.0)$ & $3(8.6)$ & $5(5.3)$ \\
\hline & Struvite & $O(0.0)$ & $2(7.4)$ & $2(6.9)$ & $2(5.7)$ & $6(6.3)$ \\
\hline & Purines & & & & & \\
\hline & Anhydrous uric acid & $1(25.0)$ & $0(0.0)$ & $5(17.2)$ & $7(20.0)$ & 13(13.7) \\
\hline & Urate ammonium & $0(0.0)$ & $0(0.0)$ & $0(0.0)$ & 3(8.6) & $3(3.2)$ \\
\hline & Cystine & $0(0.0)$ & $0(0.0)$ & $1(3.4)$ & $0(0.0)$ & $1(1.1)$ \\
\hline & All & $4(100.0)$ & $27(100.0)$ & $29(100.0)$ & $35(100.0)$ & $95(100.0)$ \\
\hline
\end{tabular}

subtype VIb) were present in most of the stones analyzed, but in a lower proportion. The frequency of whewellite in females increased with age, while in men it decreased with age.

\subsection{Sites of urinary stones}

In this study, $62.1 \%$ of the stones were located in the upper urinary tract with a left side predominance. This is in agreement with studies by Udugh et al. in Nigeria, which reported a frequency of 71\% [6] and Abbassene et al. [10] in Algeria that reported a proportion of $89 \%$.

\subsection{Composition, morphology and etiological factors of stones}

In this study, only 3 stones (2.3\%) were assessed pure, the remaining were mixed and very heterogeneous. The same findings have been reported in China. Wu and coll. reported that $2.6 \%$ of stones were pure [11]. Furthermore, we observed that the large size of stones (large average diameter of $20 \mathrm{~mm}$ ) and the consideration of minor components such as proteins, mucopolysaccharides, and others have strongly influenced the heterogeneity of the stones observed in this study. Contrary to these findings, Francisco et al. [12] in Argentina found 56.1\% of pure stones out of a total of 8854 kidney stones analyzed.
Randall's plaques were detected in only $2.3 \%$ of stones in this study. However, these plaques were observed in almost $80 \%$ of calcium stones in the United States [13, 14 ] and in more than half in France [15]. Randall's plaque [16] is a papillary calcification developed in the interstitium of the deep medulla of the kidney, near the epithelium of the papilla. Hypercalciuria is considered a major determinant in the genesis of this plaque. Based on our findings, hypercalciuria might not be an important cause of lithogenesis in our setting. This hypothesis seems to be confirmed by the low proportion (3.8\%) of stones composed mainly of weddellite (calcium-dependent form of $\mathrm{CaOx}[17])$ in this study.

Calcium oxalate is the most common component of urinary stones in most countries, including developing countries $[7,18]$. In this multi-center study, $\mathrm{CaOx}$ (essentially the monohydrate form) was the most important crystalline body. Indeed, the whewellite was identified in $97.7 \%$ of stones analyzed and $89.4 \%$ of the kernels of these stones. The Ia subtype was predominant in simple morphology and also present in many morphological associations. $\mathrm{CaOx}$ (mono and dihydrate) was the main component in $72.7 \%$ of stones, and whewellite was ten times more common than weddellite. In vivo conversion of $\mathrm{C} 2$ ( $\mathrm{CaOx}$ dihydrate) to $\mathrm{C} 1$ ( $\mathrm{CaOx}$ monohydrate), by a mechanism of punctual dissolution recrystallization, 
Table 7 Main types of stones grouped, socio-demographic, and clinical profile of patients with urolithiasis

\begin{tabular}{|c|c|c|c|c|c|}
\hline Variables & Overall $n=131(\%)$ & $\begin{array}{l}\text { Oxalate calcium } \\
n=96(\%)\end{array}$ & $\begin{array}{l}\text { Phosphates } n=18 \\
(\%)\end{array}$ & Purines $n=17(\%)$ & $p$ \\
\hline Sex & & & & & 0,068 \\
\hline Female & $37(28,0)$ & $29(30,2)$ & $7(38,9)$ & $1(5,9)$ & \\
\hline Male & $94(72,0)$ & $67(69,8)$ & $11(61,1)$ & $16(94,1)$ & \\
\hline Age & & & & & 0,035 \\
\hline$<19$ years & $6(4,6)$ & $4(4,2)$ & $1(5,6)$ & $1(5,9)$ & \\
\hline 20-39 years & $38(29,0)$ & $30(31,2)$ & $8(44,4)$ & $0(0,0)$ & \\
\hline $40-59$ years & $48(36,6)$ & $38(39,6)$ & $4(22,2)$ & $6(35,3)$ & \\
\hline$\geq 60$ years & $39(29,8)$ & $24(25,0)$ & $5(27,8)$ & $10(58,8)$ & \\
\hline Residence & & & & & $0,001^{*}$ \\
\hline Kinshasa & $116(88,5)$ & $88(91,7)$ & $11(61,1)$ & $17(100,0)$ & \\
\hline Hors Kinshasa & $15(11,5)$ & $8(8,3)$ & $7(38,9)$ & $0(0,0)$ & \\
\hline Province of origin** & & & & & $0,008^{*}$ \\
\hline West & $62(47,3)$ & $49(51,0)$ & $5(27,8)$ & $8(47,1)$ & \\
\hline North & $18(13,7)$ & $17(17,7)$ & $1(5,6)$ & $0(0,0)$ & \\
\hline Center-south & $33(25,2)$ & $22(22,9)$ & $5(27,8)$ & $6(35,3)$ & \\
\hline East & $18(13,7)$ & $8(8,3)$ & $7(39,9)$ & $3(17,6)$ & \\
\hline Urinary tract infection & & & & & $0,102^{*}$ \\
\hline Yes & $43(32,8)$ & $27(28,1)$ & $5(27,8)$ & $11(64,7)$ & \\
\hline No & $28(21,4)$ & $24(25,0)$ & $2(11,1)$ & $2(11,8)$ & \\
\hline No specified & $60(45,8)$ & $45(46,9)$ & $11(61,1)$ & $4(23,5)$ & \\
\hline Prostatic adenoma & & & & & $0,005^{*}$ \\
\hline Yes & $27(20,4)$ & $12(33,3)$ & $3(50,0)$ & $11(87,6)$ & \\
\hline No & $29(22,0)$ & $24(66,7)$ & $3(50,0)$ & $2(15,4)$ & \\
\hline Female/Child/No specified & $76(57,6)$ & $60(62,5)$ & $12(66,7)$ & $4(22,2)$ & \\
\hline Seat of stones & & & & & 0,001 \\
\hline Upper urinary tract & $82(62,6)$ & $70(72,9)$ & $9(50,0)$ & $3(17,6)$ & \\
\hline Low urinary tract & $49(37,4)$ & $26(27,1)$ & $9(50,0)$ & $14(82,4)$ & \\
\hline
\end{tabular}

*Likelihood-ratio chi-square

${ }^{* *}$ Center south: Sankuru, Kasaï, Kasaï-Central, Kasaï oriental, Haut-Lomami, Lomami, Tanganyika, Lualaba, Haut-Katanga. East: Maniema, North Kivu, South Kivu. North: Nord-Ubangi, Sud-Ubangi, Mongala, Ecuador, Tshuapa Bas-Uele Haut Uele, Tshopo, Ituri. West: Kongo central, Kinshasa, Kwango, Kwilu, Mai-Ndombe

contributes in part to the frequency of whewellite, found in $99.4 \%$ of oxalic calculations, especially in the central zone, even when the structure is typically weddellitic [19].

In France, if we consider the stones according to their main components, we observed that $\mathrm{CaOx}$ was by far the most frequent accounting for $70.3 \%$ of the stones analyzed, followed by calcium phosphates $(13.8 \%)$, carbapatite (11.4\%), and purines (9.7\%). Of these, uric acid was the most frequent (9.4\%). It was mainly observed in anhydrous form (7.9\%). Finally, most of stones in struvite accounted only for $1.6 \%$ of cases, and cystine represented approximately $1 \%$ of stones [4]. Similar to our results, Abbassene et al. [10] in Algeria find $\mathrm{CaOx}$ (majority in $75 \%$ of calculations) as the predominant major component, it is followed by uric acid (10.2\%), carbapatite (8.9\%), and struvite (3.4\%). Likewise, in this study, phosphates (13.6\%), including struvite, had the second position of the main components (the predominant IVa and IVb subtypes), and purines (12.9\%) were third. In contrast, anhydrous uric acid, the majority in $10.6 \%$ of the stones, presented itself as the second major body after whewellite. Carbapatite, the majority in $8.3 \%$ of cases, came in third position. The fairly high average age of the patients in this series ( $48.1 \pm 17.1$ years) and the significant proportion of bladder stones associated with prostatic adenoma largely explain this predominance of anhydrous uric acid compared to carbapatite. If cystine (linked to the Va subtype) was identified in a stone, opaline silica was not found in our series whereas in Burkina Faso, Dessombz et al. [20] recently found a very high incidence of opaline silica in the stones of this country, probably linked to geophagy, a practice still common in some areas in the DRC. 
Etiologically, the formation of whewellite (the most common body of stones in this study) coincides with hyperoxaluria, notably caused by insufficient diuresis and / or excessive dietary intake of oxalate. Of course, whewellite can also be derived from a crystalline conversion of weddellite [19]. The first risk factor for all stones, regardless of their chemical nature, is dehydration. As a consequence, there is an increase in lithogenic solutes concentration, which can aggravate an imbalance between promoters and inhibitors of urinary crystallization, a situation particularly frequent in lithiasis subjects. In tropical countries, hydration is important to compensate for skin loss due to heat. With regard to diet, shifts in dietary patterns are a major concern in most African countries due to their negative impact on the prevalence of chronic diseases. Traditionally, African diets were largely based on vegetables. Currently, food consumption in some African households has shifted to diets rich in fats, refined sugar, and animal-based products high in saturated fats. These so-called western diets are associated with increased adiposity, a major risk factor for the development of chronic diseases. Also, these diets exert indirect lithogenic effects by their action on the metabolism by increasing the renal excretion of crystallizable substances [21].

We found a higher proportion of proteins in stones compared to other studies. Like whewellite, proteins were present in $96.2 \%$ of stones and $89.4 \%$ of nuclei, although in small proportions (average (SD) percentage of $4.5 \%(3.2)$ ). On the morphological level, the type VI morphological association was the second most identified morphological association at the level of the nuclei (29.4\% of the morphological associations of the nuclei of women and $18.7 \%$ of men). The VIb subtype suggestive of proteinuria and possibly drug stones was the most frequent in combination or in simple morphology. If the age of our stones (translated by their hardness and a fairly large average diameter) and storage defects for some may justify a speculation on the origin of proteins on these stones, based on these findings, proteinuria might play an important role in the genesis of stones. Indeed, in addition to the described role of the intervention of a lithogenic protein matrix among the causes of the crystallization of calcium oxalate [22], a review of four crosssectional studies conducted in Kinshasa in the general population and in hospital, reported a high prevalence of proteinuria in subjects without traditional risk factor. This proteinuria was closely linked to chronic kidney disease with the prevalence of $12.4 \%$ of kidney disease in the general population [23].

\subsection{Stones composition, socio-demographic, and clinical profile}

The distribution of main components by gender revealed that females (16.2\%) had more carbapatite stones than males (5.3\%). Regarding calcium oxalate, the frequency of whewellite stones in females increased with age and conversely, in males, this frequency decreased with age over anhydrous uric acid stones. A study by Laziri et al. [24] in Morocco did not find a link between the chemical composition of stones and gender, rather, a link between the chemical composition of stones and age; weddellite seen in younger people and uric acid in the elderly.

In the United States, significant differences have been observed in the distribution of the lithiasic constituents according to geographic sites [1]. In this study, phosphates were more frequent in stones found in young patients (20-30-years-old) living in the eastern provinces. $\mathrm{CaOx}$ was more frequent in patients aged 20-59, from provinces in the western part of the DRC. Purines were more frequent in older patients, living in the city of Kinshasa. The difference in standard of living, the stress of large cities and eating habits are factors that may, at least partially explain this difference in the constituents of stones between Kinshasa and the other provinces of the DRC.

The main limitation of this study is relatively lower sample size included, which is not representative of the whole country. Thus, caution should be taken when interpreting these findings. Regardless, this is the first multi-centric study analyzing urinary stones by stereo microscopy associated with infrared spectrophotometry. However, more data are needed to study the association between the composition of urinary stones in the DRC and the dietary habits of Congolese with urolithiasis.

\section{Conclusion}

This study revealed that stones were very heterogeneous and mainly composed of whewellite (the dominant subtype Ia). Overall, whewellite was the largest main component. Like whewellite, traces of proteins (the dominant subtype VIb) are detected in several stones. These results suggest 1 ) the need for an information effort with patients to increase water intake in order to limit the frequency of concentration hyperoxaluria; 2) the need for a dietary survey and the search for urinary biological abnormalities in Congolese lithiasis patients.

\section{Abbreviations}

RDC: Democratic Republic of Congo; CaOx: Calcium oxalate; BMI: Body mass index; PACC: Amorphous carbonate calcium phosphate; OCP: Octocalcium phosphate pentahydrate. 


\section{Acknowledgements}

The authors sincerely thank the Functional Exploration Department of the Tenon Hospital in Paris, the staff of the Urology Service of the University Clinics of Kinshasa, as well as all of these hospitals and doctors who have agreed to collaborate with us in this context study.

\section{Authors' contributions}

PKDD, DMM designed, collected, interpreted, wrote and corrected the manuscript. EMM, ANM analyzed the data, read and corrected the article. JRM and EKS read and edited the article, MD and PKDD carried out the morphoconstitutional analysis of stones, and revised the manuscript, AMLP-M, MD and J-PH supervised, interpreted and edited the article. All authors have read and approved the final version of the article.

\section{Funding}

The authors received no funding for this study.

\section{Availability of data and materials}

The datasets used and/or analyzed during the current study are available from the corresponding author on reasonable request.

\section{Declarations}

\section{Ethics approval and consent to participate}

Participation of human research subjects conformed to institutional review board guidelines, applicable laws, and the World Medical Association Declaration of Helsinki. The study was approved by the ethics committee of the School of Public Health at the University of Kinshasa (Approval No. ESP/ CE/29/2020).

\section{Consent for publication}

Not applicable.

\section{Competing interests}

The authors declare that they have no competing interests.

\section{Author details}

${ }^{1}$ Department of Urology, Faculty of Medicine, University Hospital of Kinshasa, Kinshasa, Democratic Republic of Congo. ${ }^{2}$ Department of Nephrology, University Hospital of Kinshasa, Kinshasa, Democratic Republic of Congo. ${ }^{3}$ School of Public Health, University of Kinshasa, Kinshasa, Democratic Republic of Congo. ${ }^{4}$ Department of Clinical Biology, University Hospital of Kinshasa, Kinshasa, Democratic Republic of Congo. ${ }^{5}$ Department of Functional Investigations, TENON Hospital, Paris, France.

Received: 26 February 2021 Accepted: 11 July 2021

Published online: 21 July 2021

\section{References}

1. Daudon M, Traxer O, Lechevallier E, Saussine C (2008) Epidémiologie des lithiases urinaires. Prog Urol 18:802-814

2. Daudon M, Knebelmann B (2011) Epidemiology of urolithiasis. Rev Prat 61:372-378

3. Curhan GC (2007) Epidemiology of stone disease. Urol Clin North Am 34:287-293

4. Daudon M (2005) Epidémiologie actuelle de la lithiase rénale en France. Ann Urol 39:209-231

5. Sorokin I, Mamoulakis C, Miyazawa K, Rodgers A, Talati J, Lotan Y (2017) Epidemiology of stone disease across the world. World J Urol 35(9):1301-1320
6. Udugh II, Idigo FU, Chinda JY (2008) Sonographic Assessment of Urolithiasis in University of Abuja Teaching Hospital. Nigeria Ann Afr Med 17(3):106-109

7. El Kabbaj S, Meiouet F, Elamrani A (2000) Analyse des calculs urinaires par spectrophotométrie infrarouge à propos de 218 cas au Maroc. Biologie \& Santé 1(1):14-25

8. Cloutier J, Villa L, Traxer O, Daudon M (2015) Kidney stone analysis: "Give me your stone, I will tell you who you are!"World J Urol 33:157-169

9. Diangienda KD, Moningo M, Mafuta M, Punga M, Lufuma LN, Daudon M (2019) Profil épidémiologique des calculs urinaires aux Cliniques Universitaires de Kinshasa. Ann Afr Med 12(2):3220-3228

10. Abbassene F, Maizia A, Messaoudi N, Bendahmane L, Boukharouba $H$ Daudon M, Addou A (2020) Lithiase urinaire chez l'adulte dans l'ouest algérien : a propos de 1104 cas. Tunisie Médicale 98(5):396-403

11. Wu W, Yang B, Ou L, Liang Y, Wan S, Li S, Zeng G (2014) Urinary stone analysis on 12,846 patients: a report from a single center in China. Urolithiasis 42(1):39-43

12. Spivacow FR, Del Valle EE, Lores E, Rey PG (2016) Kidney stones: composition, frequency and relation to metabolic diagnostic. Medicina (Buenos Aires) 76:343-348

13. Low RK, Stoller ML (1997) Endoscopic mapping of renal papillae for Randall's plaques in patients with urinary stone disease. J Urol 158:2062-2064

14. Matlaga BR, Coe FL, Evan AP et al (2007) The role of Randall's plaques in the pathogenesis of calcium stones. J Urol 177:31-38

15. Daudon M, Traxer O, Williams JC et al (2011) Randall's plaques. In: Rao PN, Preminger GM, Kavanagh JP (eds) Urinary tract stone disease. Springer, London, pp 103-112

16. Randall A (1936) An hypothesis for the origin of renal calculus. N Engl J Med 214:234-237

17. Daudon M, Letavernier E, Frochot V, Haymann JP, Bazin D, Jungers $P$ (2016) Respective influence of calcium and oxalate urine concentration on the formation of calcium oxalate monohydrate or dihydrate crystals. C R Chim 19:1504-1513

18. Daudon M, Bounxouei B, Santa Cruz F et al (2004) Composition of renal stones currently observed in non-industrialized countries. Prog Urol 14:1151-1161

19. Daudon M, Réveillaud RJ (1984) Whewellite and weddellite: toward different etiopathogenesis. Interest of the morphological typing of the stones. Nephrologie 5:195-201

20. Dessombz A, Kirakoya B, Coulibaly G, Ouedraogo R, Picaut L, Weil R et al (2015) High prevalence of opaline silica in urinary stones from Burkina Faso. J Urol 86(6):1089-1096

21. DaudonBader MCA, Junger P (1993) Urinary calculi: review of classification methods and correlations with etiology. Scann Microsc 7:1081-1106

22. Merchant ML, Cummins TD, Wilkey DW et al (2008) Proteomic analysis of renal calculi indicates an important role for inflammatory processes in calcium stone formation. Am J Physiol Renal Physiol 295:F1254-F1258

23. Sumaili K, Krzesinski JM, Cohen E, Nseka N (2010) Epidémiologie de la maladie rénale chronique en République démocratique du Congo: une revue synthétique des études de Kinshasa, la capitale. J Nephrol 6(4):232-239

24. Laziri F, Rhazi Filali F, Oussama A, Soulaymani A, Qarro A, Lezrek M (2010) Facteurs impliqués dans l'épidémiologie des calculs urinaires Marocains. J Maroc Urol 19:9-14

\section{Publisher's note}

Springer Nature remains neutral with regard to jurisdictional claims in published maps and institutional affiliations. 